\title{
A Female Color Ornament Honestly Signals Fecundity
}

\author{
Deike U. Lüdtke* and Katharina Foerster \\ Comparative Zoology, Institute for Evolution and Ecology, University of Tübingen, Tübingen, Germany
}

In many species, particularly in ectothermic vertebrates, not only males but also females show bright body colorations. In Alpine newts, Ichthyosaura alpestris, both sexes have colorful orange bellies. This coloration varies in redness (yellowish to dark orange) among individuals, and previous work has shown that courting males preferred females with more orange bellies. Because males in this species are likely to be limited in their mating capacity, selection would favor this preference if this coloration honestly signals female quality. In this study, we investigated whether female belly coloration can predict individual fecundity in which case males might have the chance to fertilize more eggs when they choose to mate with a more ornamented female. We found that more orange females were more fertile than less orange ones. Additionally, we saw that more ornamented females could lay their eggs faster, which means that they ceased egg laying at a similar

OPEN ACCESS

Edited by:

Renoult P. Julien,

UMR5175 Centre d'Ecologie

Fonctionnelle et Evolutive (CEFE), France

Reviewed by:

Rebecca E. Adrian (Koch) Monash University, Australia Nuno Miguel Monteiro, University of Porto, Portugal

*Correspondence:

Deike U. Lüdtke deike.luedtke@uni-tuebingen.de

Specialty section:

This article was submitted to Behavioral and Evolutionary Ecology, a section of the journal

Frontiers in Ecology and Evolution

Received: 24 July 2019

Accepted: 23 October 2019

Published: 12 November 2019

Citation:

Lüdtke DU and Foerster K (2019) A Female Color Ornament Honestly Signals Fecundity.

Front. Ecol. Evol. 7:432. doi: 10.3389/fevo.2019.00432 time as less ornamented females despite the greater number of eggs. This suggests that female color can convey quality advantages in a species with no sex-role reversal much in the same way as male colors can, making female ornaments subject to sexual selection acting directly on them.

Keywords: alpine newt, fecundity, female ornament, female quality, Ichthyosaura alpestris, nuptial coloration, sexual selection

\section{INTRODUCTION}

Several theories have been put forward to explain the presence of secondary sexual ornaments. One well-documented mechanism for the evolution of such ornaments acts when that ornament functions as a quality indicator that provides a benefit during mate choice to both, the signaler, and the receiver. Since an individual may benefit by choosing a high-quality partner to mate with through direct (e.g., Price et al., 1993; Iwasa and Pomiankowski, 1999) or indirect benefits (e.g., Kirkpatrick and Barton, 1997), an exact assessment of the quality of a sexual partner may be substantially important for the choosing individual (reviewed in Kokko et al., 2003).

Many studies have demonstrated female preferences for male ornaments and have investigated different benefits that females might gain from choosing a highly ornamented male, suggesting that the ornaments can visualize quality in males. These benefits can include higher fertility of males (Pitcher and Evans, 2001), better paternal care (Hoelzer, 1989), or they could be associated with less pathogen infections (e.g., Ressel and Schall, 1989). However, benefits are not always as obvious. Females could also obtain offspring in better condition (health: Barber et al., 2001; or size: Parker, 2003) or highly ornamented males can provide their offspring with genes that make them more attractive as mating partners (e.g., Gwinner and Schwabl, 2005).

Female ornamentation has long been regarded as non-adaptive correlations to male ornaments (reviewed in Nordeide, 2002; Kraaijeveld et al., 2007). They were thought to appear through a 
genetic link between the male and the female ornament, and the selection acting on the male ornaments (Lande, 1980). However, a growing number of investigations prove these assumptions not to be universally applicable.

Although studies on female ornamentation are not as numerous, we now know that in some species, males may also base their choice on female secondary sexual ornaments. This was predominantly documented for sex-role reversed species (e.g., Berglund and Rosenqvist, 2001), but an increasing number of studies also demonstrate a male preference for ornamented females in otherwise conventional sex-roles (e.g., Torres and Velando, 2005; Baldauf et al., 2011; LaPlante, 2015; Belliure et al., 2018; Lüdtke and Foerster, 2018). Females of the rock sparrow, Petronia petronia, for example, have a yellow breast patch and males were found to court females with a smaller or experimentally reduced patch size less intensely and less frequently (Griggio et al., 2005).

This evidence, together with reports on male choosiness even in polygynous species (Servedio and Lande, 2006) suggests that the intensity of male choosiness is more dynamic than previously thought (Clutton-Brock, 2009; Clutton-Brock and Huchard, 2013). In fact, mutual mate choice, that is when both sexes exert mate choice, is rather common (Clutton-Brock, 2009; Rosenqvist and Berglund, 2011; Rosenthal, 2017) and the intensity of male choosiness is expected to vary with the availability of partners relative to its mating capacity (Edward and Chapman, 2011).

Consequently, female nuptial signals can well have a selective advantage (reviewed in Kraaijeveld et al., 2007). On the one hand, females may use them as an aggressive signal predominantly in intrasexual competition (Beeching et al., 1998), as it is the case in convict cichlids, Cichlasoma nigrofasciatum. Only females of this species typically develop an orange ventral coloration and only females seemed to use this color as a visual signal. Females were more aggressive toward more brightly colored individuals than intermediate ones. On the other hand, nuptial signals can also function as a signal to advertise females' reproductive state or individual quality. When this is the case, males benefit by mating with highly ornamented females. In species without maternal care, female quality is characterized by fecundity, the quality of the eggs or offspring performance after birth or hatching. For choosy males, any trait that reflects such quality aspects would be relevant. For example, the plumage color of blue tit females, Cyanistes caeruleus, correlated positively with clutch size, fledgling success, and recruitment (Doutrelant et al., 2008). Such a correlation between colorful ornaments and individual quality has also been shown for other birds (e.g., Pilastro et al., 2003) and some fish (e.g., Massironi et al., 2005; Kekäläinen et al., 2010). Further studies on other taxa that demonstrate a correlation between a colorful ornament and individual quality in females are currently lacking.

With this study, we want to extend the knowledge about the function of female coloration and the potential for selection on female nuptial signals in a Eurasian amphibian, the Alpine newt (Ichthyosaura alpestris). Alpine newt males and females have colorful orange bellies that vary naturally in their color hue (Kopecký and Šichtar, 2014; own obs.). Body colorations that appear red, orange, or yellow are caused by carotenoids or pteridines that accumulate in feathers or skin cells (Olson and Owens, 1998; Griffith et al., 2006; Weiss et al., 2012). Ornaments composed of such pigments have often been reported to communicate quality advantages of the bearer (reviewed in Weiss et al., 2011). For example, pigment content has been suggested to correlate with immune defense especially in mammals (Huber et al., 1984; Chew and Park, 2004). Whether these compounds directly enhance immune responses or provide important precursors for other compounds is, however, still debated (e.g., Pérez-Rodríguez, 2009; Koch et al., 2018). Ornamental pigment content has also been suggested to relate to individual reproductive potential. Carotenoid-based coloration was reported to correlate positively with fecundity in a bird (Doutrelant et al., 2008) and a fish (Svensson, 2006), and the pteridine-based ornament of female striped plateau lizards, Sceloporus virgatus, was positively related to the total amount and concentration of yolk antioxidants (Weiss et al., 2011). These findings suggest that colorful individuals cope better with immune challenges and are better able to allocate their resources to reproduction.

Both carotenoid and pteridine pigments were found in the belly skin of Alpine newts (Günder, 1954) and other newt species (e.g., Obika, 1963; Matsui et al., 2002). We therefore expect that the belly pigmentation might function as nuptial ornamentation in this species. We recently found that male Alpine newts exhibited preference toward certain females (Lüdtke and Foerster, 2018). Males spent more time courting larger females and females that had more orange bellies. However, for male choosiness to evolve, males are expected to be limited in their mating capacity and females are expected to vary in quality (Gwynne, 1991; Kokko and Monaghan, 2001). Male Alpine newts have comparatively high mating costs (reviewed in Thiesmeier and Schulte, 2010). They engage in a time consuming mating ritual (see Arntzen and Sparreboom, 1989) and are most likely limited in their mating capacity in terms of sperm expenditure (see below). Males would gain fitness advantages if they mate with a female that lays more eggs. If females vary in the amount of eggs they lay, males should be choosy and invest more into females that are more fecund. Therefore, males should choose more orange females if this color is an honest signal for fecundity.

In this study, we investigated whether Alpine newt females with more orange bellies lay more eggs. We hypothesize that the color intensity is a signal for the number of eggs a female lays and hence a signal for individual quality. We also tested whether more orange females laid their eggs faster compared to less orange ones.

\section{MATERIALS AND METHODS \\ Study Species}

Ichthyosaura alpestris is a medium-sized aquatic salamander with its main distribution in Central Europe (Thiesmeier and Schulte, 2010). They mate and oviposit in water bodies during spring to early summer but spend the rest of the year in a terrestrial phase. Alpine newts are sexually dimorphic in size and body shape, as 


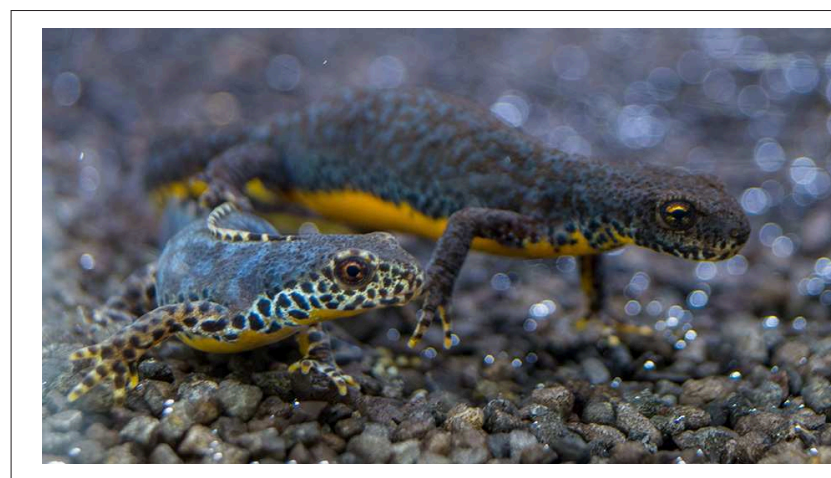

FIGURE 1 | Male (left) and female (right) Alpine newt, Ichthyosaura alpestris.

well as in their dorsal and lateral coloration. Yet, both sexes show strikingly orange bellies (Figure 1).

During courtship males attract females with a complex but stereotypic suite of behaviors (Halliday, 1977; Arntzen and Sparreboom, 1989). They transfer sperm in form of spermatophores that they deposit on the substrate and try to guide the females over them. Unfortunately, many of those spermatophores are lost, because females frequently miss to take them up with their cloaca. Observations show that females pick up only $31 \%$ (or less) of deposited spermatophores (Halliday, 1977, 1990). Males probably enter the breeding season with a limited number of sperm because spermiogenesis is most likely completed during autumn and spermatozoa are stored until the next breeding season as described for smooth newts, Lissotriton vulgaris (see Verrell et al., 1986). During the mating season in early spring, Alpine newts gather in often crowded ponds, where high mating activity and scramble competition is observable at any time of the day (e.g., Blab and Blab, 1981; Lüdtke and Foerster, 2019). When courting a single female, males may sequentially deposit several spermatophores (Halliday, 1977; Maag, 2013; pers. obs.), and each male courts a large number of females if they are available to him (own observation in large group aquarium). Given the long duration of the Alpine newt breeding season (several weeks to a few months, Blab and Blab, 1981), we have thus reason to assume that a male's sperm capacity is limited and that any loss of spermatophores is costly for males.

After mating, females lay their eggs by individually wrapping them into submersed aquatic plant supports (Miaud, 1994, 1995; own obs.). Individual females can lay between 100 and 500 eggs (Miaud, 1994). The average number of counted oocytes from wild caught individuals was $258(N=8$; Thomas et al., 2002), and 293 $(N=7$; von Lindeiner, 1992). In laboratory experiments, female fecundity was observed to fluctuate between 20 and 271 eggs (reviewed in Thiesmeier and Schulte, 2010). Although female body size may be a proxy for fecundity in many species (e.g. Honěk, 1993; Bonduriansky, 2001; Wong and Svensson, 2009; Eddy et al., 2016), reports about Alpine newts on that matter are not consistent. Where Miaud (unpublished data, cited in Miaud and Merilä, 2001) reported a positive correlation between body size and egg number, such a relationship could not be confirmed when Thomas et al. (2002) investigated fecundity by counting the number of oocytes.

\section{Lab Population and Husbandry}

The study was carried out at the University of Tübingen, Germany, from 10 March to 20 July 2017. The lab population consisted of wild individuals caught in 2011 and 2012 from the surrounding of the city of Tübingen, and their descendants, all born in the lab between 2011 and 2014. The founder population included 243 individuals (125 females and 118 males), collected from two separate wild subpopulations. After hibernation, we separated males and females and kept them in aquaria at a maximum density of 15 individuals per aquarium $(\approx 721$ each; 60 $\times 60 \times 38 \mathrm{~cm} \mathrm{lwh})$. We regulated ambient air temperature to be between 12 and $16^{\circ} \mathrm{C}$ and set the photoperiod to 12:12 LD (light from 8:00 to 20:00). Home aquaria were equipped with black gravel, shelters (brick stones with many holes), water plants, and an above-water platform. We fed the newts with red mosquito larvae and water fleas (Daphnia sp.) ad libitum three times a week. Before we transferred the females into special oviposition aquaria, we placed males and females together into a large-group aquarium for four days to ensure insemination as described in Lüdtke and Foerster (2019). We randomly divided the newts into three groups with 36 individuals and a 50:50 sex ratio. We introduced the groups into the mating aquarium in succession.

\section{Oviposition and Egg Handling}

After 4 days in the mating aquarium, where females had free access to several males, we transferred the females $(N=54)$ into oviposition aquariums $(\approx 401$ each; $60 \times 60 \times 38 \mathrm{~cm}$ lwh) that were divided into three same-sized compartments $(20 \times 60 \times 38 \mathrm{~cm} \mathrm{lwh})$. Each female was placed in one of these compartments. We supplied each compartment with black gravel, a small PVC tube $(10 \mathrm{~cm}$ length, $2.5 \mathrm{~cm} \varnothing)$ as a hiding place, a platform above the water level and a water plant (Ludwigia repens in terracotta supports) to lay eggs on. The first group of 18 females was introduced into the oviposition aquariums on 10 March, the second group on 18 March, and the last one on 22 March. One female escaped from the oviposition aquarium during the experiment and was excluded from the analysis. Every 4-7 days, we replaced plants, scanned the compartments for eggs that were laid outside of the provided plant and counted the total number of eggs a female had laid. To accurately define the number of eggs we carefully removed each counted egg with forceps and scanned the plant the next day for any remaining eggs. If a female did not lay a single new egg in 4 weeks, we assumed that it ceased laying and released it into the home aquarium in the husbandry.

\section{Color and Size Measurements}

Prior to the experiment, we measured reflectance of the ventral sides to quantify the color of the females' bellies. We measured reflectance in two different regions (belly and throat) from 380 to $700 \mathrm{~nm}$ using a spectroradiometer (SpectraScan PR 670, Photo Research Inc., Syracuse, NY, U.S.A.) (see also Lüdtke and Foerster, 2018). Each reflectance spectrum was calculated relative to a polytetrafluoroethylene (PTFE 98) white reflectance standard (Berghof Fluoroplastic Technology GmbH, Eningen, Germany) with the program Spectrawin 5.0 (Avantes, Apeldoorn, The Netherlands). We used two indices to describe color. 
We calculated hue (peak wavelength) as the wavelength where reflectance is at its maximum, and chroma (spectral purity) which describes the relative color saturation in a wavelength range of interest. We calculated chroma as the reflectance sum over the red range from $605 \mathrm{~nm}$ to the maximally measured wavelength $(700 \mathrm{~nm})$, divided by the total reflectance sum (R package pavo, Maia et al., 2013). For both, hue and chroma, we averaged the two measured regions (belly and throat) and refer to the mean as that female's belly hue or chroma, respectively. We measured snout-vent length $(\mathrm{SVL})(5.2 \pm 0.3 \mathrm{~cm})$ when the animals were under anesthesia and weighed them $(5.00 \pm 0.88 \mathrm{~g})$ just before they entered their individual oviposition aquaria. Additionally, we weighed the females again after they finished the experiment.

\section{Statistics}

We performed all statistical analyses using $\mathrm{R}$ version 3.5.1 ( $\mathrm{R}$ Core Team, 2018) and all data summaries are reported as means $\pm \mathrm{SD}$. We excluded females from the statistical analyses that laid $<20$ eggs (12 individuals). We considered those females not to be fully ready to lay, either because they were still waiting for additional copulations or because their reproductive rhythm was delayed with respect to the other females. Although reports suggest that lab-reared amphibians are not as colorful as conspecifics found in the wild (e.g., Steinicke, 1976; Frost and Robinson, 1984; Matsui et al., 2002), we did not want to include individuals in our investigations that had an unnatural color scheme (more than 5\% outside the range of the natural occurring range). As a reference, we compared the chroma values of newts in our experiment to 36 wild females that were captured in the population where our founder individuals originated from, measured in the same way as described before, and released into the wild in 2013 (chroma: $0.606 \pm 0.023$, range: 0.552-0.645; unpublished raw data). We then identified three experimental females that were unusually faint (chroma: 0.500, 0.514, and 0.521) and suspected that they were unable to store certain pigments in their skin. We therefore excluded two more females from the analyses (as the third was already excluded because of low egg numbers, see above). We finally used 39 females for all analyses.

The data for the total number of eggs did not show a normal distribution, nor did it fit a Poisson distribution. We thus applied non-parametric statistics: we tested the effect of hue, chroma, size, and weight on the total number of laid eggs with Kendall rank correlations. To test whether the daily laying activity was individually different, we also investigated the individual curves of the cumulative number of eggs. We performed linear mixed models (function lmer, package lme4; Bates et al., 2015) and included the day since introduction to the laying-compartment, either hue or chroma, and their interactions as fixed factors. We also included either SVL or weight, and their interaction with the day in the models. In all models, we log-transformed day (decadic logarithm) to fit the curve of the data. Apart from day, we standardized all continuous variables so that their means were zero and their standard deviations one. As random factors, we included female ID to account for repeated measures on each female, and mating group to account for random variance between the three groups that were mating in succession. We also included a random slope for the covariate day dependent on ID to account for unsystematic variance between the females (KornerNievergelt et al., 2015). For the parameter estimates (presented in the table) and model predictions (presented in the figure), we obtained 95\% credible intervals (CrI) by using Bayesian statistics (Bolker et al., 2008). We calculated the exact uncertainty of model predictions (Gelman and Su, 2016) by using 10000 simulated random values obtained from the joint posterior distribution of the model parameter. We concluded that a parameter was different from zero if the $95 \%$ credible interval of its estimate did not include zero (Bolker et al., 2008). We present the Akaike Information Criterium for small sample size $\left(\mathrm{AIC}_{\mathrm{c}}\right)$ for each model and compare models based on the difference in $\mathrm{AIC}_{\mathrm{c}}$ $\left(\Delta \mathrm{AIC}_{\mathrm{c}}\right)$.

\section{Ethical Note}

Maintenance and handling of the newts were conducted in accordance with German animal welfare law (Tierschutzgesetz) and FELASA guidelines. All experiments were approved by the local veterinary office "Veterinäramt, Regierungspräsidium Tübingen," under the license number ZO 5/15.

\section{RESULTS}

\section{Total Number of Eggs and Laying Duration}

Female weight was not correlated to hue or chroma, and SVL was not correlated to hue (all $p>0.05$ ). However, females with larger SVL were more orange as measured by chroma $\left(r_{p}=0.446, p=\right.$ 0.001 ). Three females did not lay a single egg and were excluded from the analyses. Additionally, we excluded the ones that laid $<20$ eggs from the analyses $(N=9)$, as well as the three females that were more than $5 \%$ less orange than females in the natural population (see Figure S1). Among all other females, the range of chroma was $0.535-0.642(0.581 \pm 0.025)$ and the total number of laid eggs varied between 23 and 451 (158.54 \pm 106.60$)$.

We found no relationship between a female's weight and the number of eggs it laid ( $r_{\tau}=0.041, p=0.717$; Figure 2A); nor did we find a relationship between a female's SVL and the number of eggs $\left(r_{\tau}=0.051, p=0.660\right.$; Figure 2B). However, females lost $0.72 \pm 0.55 \mathrm{~g}$, on average, during oviposition, although this weight loss was not correlated to number of eggs $\left(r_{\tau}=0.020\right.$, $p=0.856)$.

When we analyzed the effect of the two measurements of belly color (hue and chroma) on the total number of eggs, we found that more orange females (females with a higher hue and higher chroma value) laid significantly more eggs than less orange females (hue: $r_{\tau}=0.248, p=0.031$; chroma: $r_{\tau}=0.220, p=$ 0.049; Figures 2C,D). The five females with the lowest hue in our study laid on average $92.20 \pm 69.52$ eggs, while the four females with the highest hue produced on average $278.25 \pm 181.44$. For chroma, the five least orange females (lowest chroma value) laid on average $44.8 \pm 27.29$ eggs, while the five most orange females (highest chroma value) produced on average 159.29 \pm 106.61 eggs.

We observed variation in the laying duration of the females. They laid eggs between 6 and 120 days $(62.38 \pm 21.47)$, but there was no correlation between belly color and the number of days a 


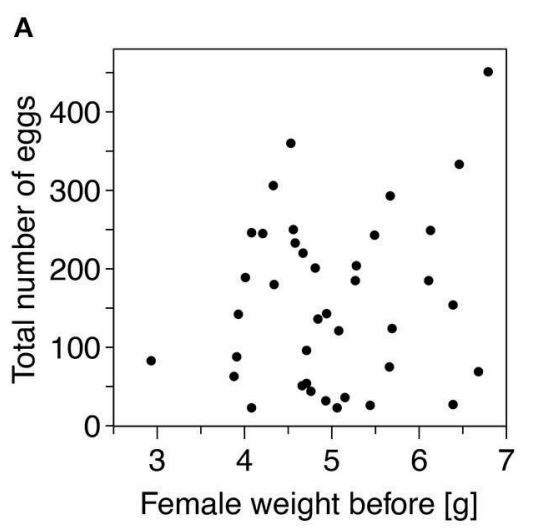

C

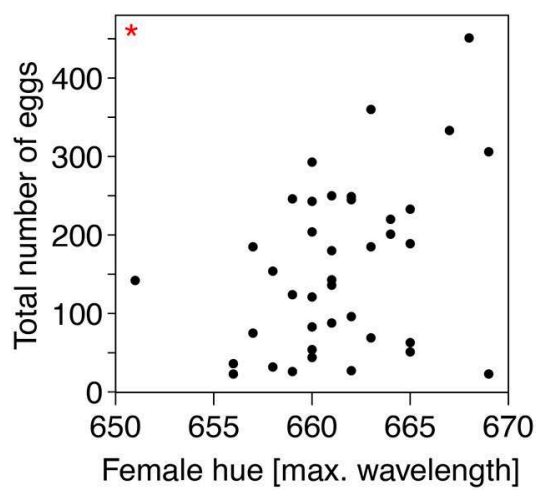

B

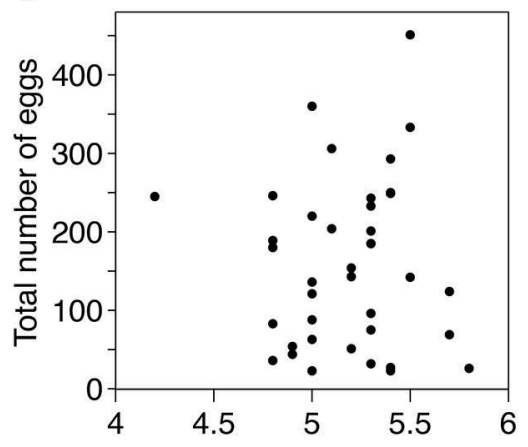

Female snout-vent length [cm]

D

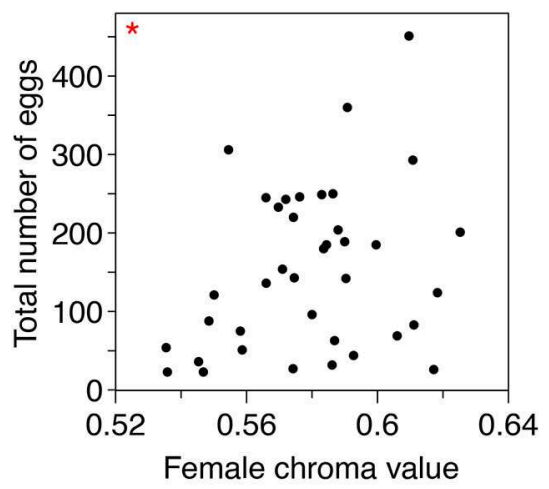

FIGURE 2 | Scatterplots illustrating the relationships between number of laid eggs and (A) female weight before the experiment started, (B) female snout-vent length (SVL), (C) female belly hue, and (D) female belly chroma. The red asterisks indicate significant correlations $(p<0.05)$. $N=39$.

female laid eggs (hue: $r_{p}=0.251, p=0.123$; chroma: $r_{p}=0.277$, $p=0.088)$.

\section{Daily Cumulative Egg Numbers}

Females with varying belly color showed differences in the daily cumulative egg numbers. The slopes of the interactions between day (log-transformed) and hue or chroma indicate how fast females with different belly color laid their eggs. When we included the weight of the female as covariate in both models, we found a significant effect of the interaction between day and hue as well as between day and chroma on the cumulative egg numbers (Table 1). Females with more orange bellies laid their eggs faster than less orange females (Figure 3A). In the other two models, we used SVL as a covariate, instead of weight (Table 1). Here, we found the same significant interaction effect (Figure 3B). For hue, the first model with weight explained the data better than the one with SVL $\left(\Delta \mathrm{AIC}_{\mathrm{c}}>2.0\right)$, but since both models with chroma explained the data similarly well ( $\Delta$ $\mathrm{AIC}_{\mathrm{c}}<2.0$; see Table S1), we computed an averaged model. This averaged model suggested again that females with a higher chroma value laid their eggs faster, than females with lower value (see Table S2). This difference was particularly obvious when a female started to lay eggs: in the first 19 to 21 days, the four most orange females (according to hue) laid on average 176.25 \pm 111.40 , while the five least orange females laid only $66.4 \pm$ 51.24 eggs on average. When we compare the females with the highest and lowest chroma values we found that the five most orange females laid on average $99.8 \pm 71.21$ eggs, while the five least orange females produced only $39.8 \pm 25.15$ eggs on average. Body size and weight did not affect the speed of egg laying: both, the interaction between day and SVL and the interaction between day and weight, were not significant in any of the tested models.

\section{DISCUSSION}

We showed that the intensity of a female's nuptial ornament had an influence on some indicators of reproductive quality. Therefore, the belly coloration of female Alpine newts might indeed function as an honest signal for fecundity. Less orange females laid their eggs more slowly, compared to more orange females. Further, we found that less orange females laid considerably fewer eggs than females with a more orange belly.

In many species, yellow, orange, or red colors in the skin or plumage are based on carotenoids (Blount and McGraw, 2008) or pteridines (e.g., amphibians: Ziegler-Günder, 1956; birds: McGraw, 2006). The intensity of these colors is positively 
TABLE 1 | Estimates, standard errors, and their 95\% credible intervals from the different linear mixed models for daily cumulative egg numbers (A) with weight and (B) with SVL as a covariate.

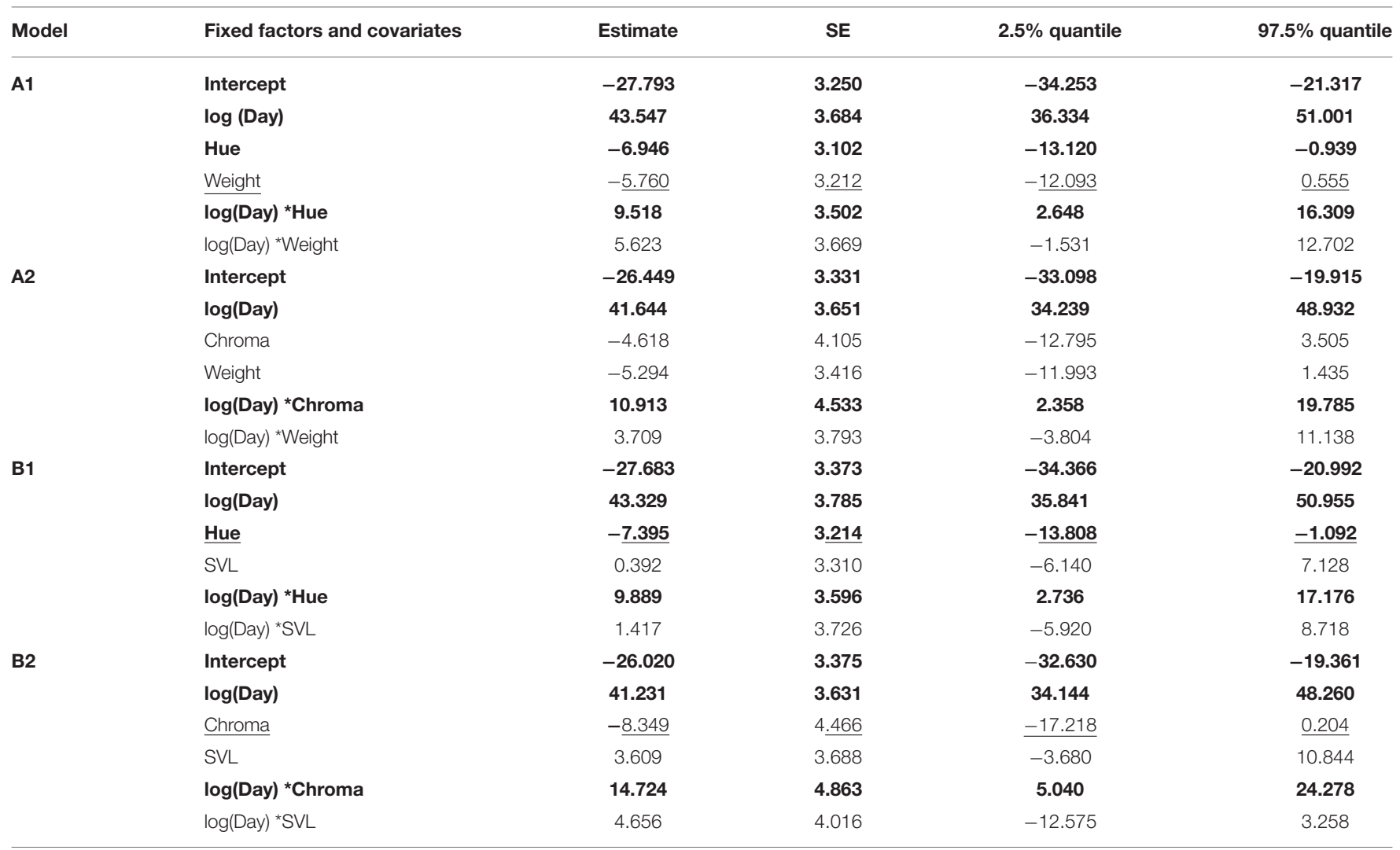

The presented quantiles limit the 95\% credible interval. Significant effects are shown in bold and trends are underlined. $N=39$.
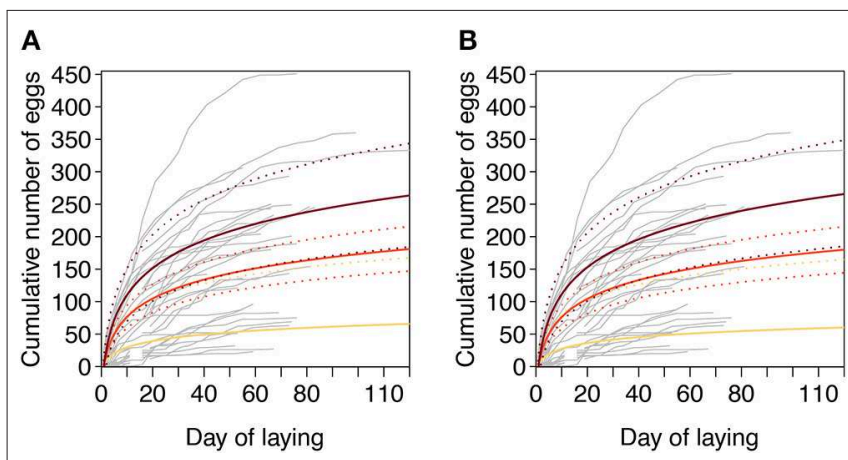

FIGURE 3 | Model predictions of the cumulative number of eggs for minimum (yellow line), mean (red line), or maximum (dark red line) hue values. Gray lines represent the raw data from 39 females. Each curve represents the cumulative number of eggs laid up to each day by each individual female. Fitted values (solid lines), predicted from an LMM, with 95\% credible intervals (dashed lines) are given assuming average values for (A) weight and (B) SVL as independent variables in the model. $N=39$.

correlated with pigment concentration. In striped plateau lizards, Sceloporus virgatus, for example, more colorful individuals had a higher concentration of drosopterin in their skin, a pterine that causes the orange color patches on the throat of this species (Weiss et al., 2012). In male three-spined sticklebacks,
Gasterosteus aculeatus, the intensity of the red belly coloration correlated positively with astaxanthin concentrations in the tissue, a carotenoid that fish take up through their diet (Barber et al., 2000).

Both of these pigment classes were suggested to enhance immune system functions (e.g., Huber et al., 1984; Chew and Park, 2004; Hõrak et al., 2004). Carotenoids, for example, are well-known as effective antioxidants (Britton, 2008; Fiedor and Burda, 2014) and pteridines can also act antioxidatively under certain conditions (Oettl and Reibnegger, 2002). Therefore, colorful individuals might have an advantage in coping with oxidative stress and are hence better able to allocate their resources into the production of viable eggs. This was shown for blue tits, Cyabistes caeruleus, where female coloration was positively correlated to number of eggs when females were forced to produce a replacement clutch (Doutrelant et al., 2008), and for the two-spotted goby, Gobiusculus flavescens, where more colorful females produced larger clutches (Svensson, 2006). Our result show that Alpine newt females with more orange bellies also laid more eggs. Not only the number of eggs can be advertised by the color of the ornament but also the quality of those eggs. In striped plateau lizards, the color of the ornament was positively correlated with the concentration and total amount of yolk antioxidants (Weiss et al., 2011). This suggests that colorful females might also produce eggs of higher 
quality and provide better yolk content for the early growth phase of embryos. Whether more orange Alpine newt females produce higher quality eggs remains to be tested.

In addition to a higher number of eggs, we also found that more orange females laid their eggs faster than less orange females. As a result, more orange females ceased egg laying at a similar time as less orange females. Female Alpine newts may be selected to lay their eggs speedily, for two reasons: First, European newts spend most of their time on land (Taylor and Guttman, 1977), and they enter water bodies only during the breeding period. To ensure that the larvae have enough time to metamorphose and leave the water before the next terrestrial phase starts, it would be advantageous to lay eggs fast after insemination. Second, female newts compete for access to laying substrate (small leafed water plants), and newt larvae compete for food in crowded breeding ponds. In both cases, it is probably advantageous to be among the first competitors present.

Our results suggest that belly coloration can be an important signal to determine the individual quality of Alpine newt females. Because males complete spermiogenesis during autumn and store mature sperm until the next breeding season, they are likely to be limited in the total sperm numbers that are available during one mating season (Verrell, 1986). Sperm stores may hence deplete over the course of the breeding season. During a single courtship ritual, males deposit often more than one spermatophore if they are not interrupted by conspecifics (Halliday, 1977; own observation). Within successively deposited spermatophores, the number of spermatozoa decreased continuously (Maag, 2013). This suggests that males are sperm limited even within a particular day during the mating season, as multiple courtships per day (often with various partners) are common in this species (own observation). To invest the available sperm optimally, male Alpine newts should decide to court very fecund females or females whose eggs have a high reproductive value. Our findings suggest that by choosing to court more orange females (Lüdtke and Foerster, 2018), Alpine newt males gain adaptive advantages through a potentially higher number of fertilized eggs. Further, through the speedy laying pattern of orange females, there is a better chance that a high number of these eggs will be deposited on suitable substrate, and that a high number of hatchlings will be born early enough to get a head start in their development compared to other competing larvae in the pond. Since female belly color correlated with fecundity and with laying speed, it can function as an easy-to-detect target for male choice.

In a previous study, we found indeed that male Alpine newts courted more orange bellied females for longer than less orange ones (Lüdtke and Foerster, 2018). In that study, however, we also found that males courted longer for larger females. Despite anecdotal evidence that body size positively correlates with egg numbers in this species (Miaud and Merilä, 2001), other studies could not confirm such a relationship (Thomas et al., 2002) nor could we find a correlation between female size or female body weight and number of eggs laid in this experiment. This suggests that female size does not indicate fecundity in Alpine newts. Female size could nevertheless correlate to other aspects of reproductive value, such as the size of the eggs. In spadefoot toads, Spea multiplicata, for example, larger females laid larger eggs and larger eggs produced larger tadpoles (Martin and Pfennig, 2010). Larger body size, in turn, would greatly affect the tadpoles' survival and hence the fitness of their parents. It remains to be shown whether female body size or body weight advertise any component of female reproductive value in Alpine newts.

In conclusion, our results provide experimental evidence that female belly coloration of Alpine newts can function as an honest signal for individual quality. Males could consequently benefit when they choose to mate with a more orange female. The relation between female belly color and fecundity can further explain the evolution of male preference for a female ornament. The results from this study, together with our previous finding that males did indeed prefer more orange females in mate choice experiments, lead us to conclude that in Alpine newts, female belly color is subject to sexual selection acting directly on females.

\section{DATA AVAILABILITY STATEMENT}

The datasets generated for this study are available on request to the corresponding author.

\section{ETHICS STATEMENT}

The animal study was reviewed and approved by Regierungspräsidium Tübingen, Referat 35.

\section{AUTHOR CONTRIBUTIONS}

All authors conceived and designed the experiments. DL performed the experiments and the data collection, analyzed the data and wrote the manuscript. KF revised and edited the manuscript. All authors read and approved the final manuscript.

\section{ACKNOWLEDGMENTS}

We acknowledge support by the Open Access Publishing Fund of the University of Tübingen. We also thank Martina Hohloch for her patience when counting hundreds of newt eggs, Nico Michiels for the provision of spectrometric equipment and technical advice, Dorothee Fischer for statistical advice, René Schädlich for the picture of the courting newts, and the entire staff at the Comparative Zoology Group, University of Tübingen, for their assistance.

\section{SUPPLEMENTARY MATERIAL}

The Supplementary Material for this article can be found online at: https://www.frontiersin.org/articles/10.3389/fevo. 2019.00432/full\#supplementary-material 


\section{REFERENCES}

Arntzen, J. W., and Sparreboom, M. (1989). A phylogeny for the old world newts, genus Triturus: biochemical and behavioural data. J. Zool. 219, 645-664. doi: 10.1111/j.1469-7998.1989.tb02606.x

Baldauf, S. A., Bakker, T. C. M., Kullmann, H., and Thünken, T. (2011). Female nuptial coloration and its adaptive significance in a mutual mate choice system. Behav. Ecol. 22, 478-485. doi: 10.1093/beheco/arq226

Barber, I., Arnott, S., Braithwaite, V., Andrew, J., and Huntingford, F. (2001). Indirect fitness consequences of mate choice in sticklebacks: offspring of brighter males grow slowly but resist parasitic infections. Proc. R. Soc. London B Biol. Sci. 268, 71-76. doi: 10.1098/rspb.2000.1331

Barber, I., Arnott, S. A., Braithwaite, V. A., Andrew, J., Mullen, W., and Huntingford, F. A. (2000). Carotenoid-based sexual coloration and body condition in nesting male sticklebacks. J. Fish Biol. 57, 777-790. doi: 10.1111/j.1095-8649.2000.tb00274.x

Bates, D., Mächler, M., Bolker, B., and Walker, S. (2015). Fitting linear mixedeffects models using lme4. J. Stat. Softw. 67, 1-48. doi: 10.18637/jss.v067.i01

Beeching, S. C., Gross, S. H., Bretz, H. S., and Hariatis, E. (1998). Sexual dichromatism in convict cichlids: the ethological significance of female ventral coloration. Anim. Behav. 56, 1021-1026. doi: 10.1006/anbe.1998.0868

Belliure, J., Fresnillo, B., and Cuervo, J. J. (2018). Male mate choice based on female coloration in a lizard: the role of a juvenile trait. Behav. Ecol. 29, 543-552. doi: 10.1093/beheco/ary005

Berglund, A., and Rosenqvist, G. (2001). Male pipefish prefer ornamented females. Anim. Behav. 61, 345-350. doi: 10.1006/anbe.2000.1599

Blab, J., and Blab, L. (1981). Quantitative analysen zur phänologie, erfassbarkeit und populationsdynamik von molchbeständen des kottenforstes bei bonn. (Amphibia: Caudata: Salamandridae). Salamandra 17, 147-172.

Blount, J. D., and McGraw, K. J. (2008). "Signal Functions of Carotenoid Colouration," in Carotenoids. Volume 4: Natural Functions, eds G. Britton, S. Liaaen-Jensen, and H. Pfander (Basel: Birkhäuser Verlag), 213-236. doi: 10.1007/978-3-7643-7499-0_11

Bolker, B. M., Brooks, M. E., Clark, C. J., Geange, S. W., Poulsen, J. R., Stevens, M. H. H., et al. (2008). Generalized linear mixed models: a practical guide for ecology and evolution. Trends Ecol. Evol. 24, 127-135. doi: 10.1016/j.tree.2008.10.008

Bonduriansky, R. (2001). The evolution of male mate choice in insects: a synthesis of ideas and evidence. Biol. Rev. Camb. Philos. Soc. 76, 305-339. doi: $10.1017 /$ S1464793101005693

Britton, G. (2008). "Functions of intact carotenoids," in Carotenoids. Volume 4: Natural Functions, eds G. Britton, S. Liaaen-Jensen, and H. Pfander (Basel: Birkhäuser Verlag), 189-212. doi: 10.1007/978-3-7643-7499-0_10

Chew, B. P., and Park, J. S. (2004). Carotenoid action on the immune response. J. Nutr. 134, 257S-261S. doi: 10.1093/jn/134.1.257S

Clutton-Brock, T. (2009). Sexual selection in females. Anim. Behav. 77, 3-11. doi: 10.1016/j.anbehav.2008.08.026

Clutton-Brock, T. H., and Huchard, E. (2013). Social competition and selection in males and females. Philos. Trans. R. Soc. B Biol. Sci. 368, 20130074-20130074. doi: 10.1098/rstb.2013.0074

Doutrelant, C., Grégoire, A., Grnac, N., Gomez, D., Lambrechts, M. M., and Perret, P. (2008). Female coloration indicates female reproductive capacity in blue tits. J. Evol. Biol. 21, 226-233. doi: 10.1111/j.1420-9101.2007.01451.x

Eddy, S. L., Wilburn, D. B., Chouinard, A. J., Doty, K. A., Kiemnec-Tyburczy, K. M., and Houck, L. D. (2016). Male terrestrial salamanders demonstrate sequential mate choice based on female gravidity and size. Anim. Behav. 113, 23-29. doi: 10.1016/j.anbehav.2015.12.016

Edward, D. A., and Chapman, T. (2011). The evolution and significance of male mate choice. Trends Ecol. Evol. 26, 647-654. doi: 10.1016/j.tree.2011.07.012

Fiedor, J., and Burda, K. (2014). Potential role of carotenoids as antioxidants in human health and disease. Nutrients 6, 466-488. doi: 10.3390/nu6020466

Frost, S. K., and Robinson, S. J. (1984). Pigment cell differentiation in the fire-bellied toad, Bombina orientalis. I. Structural, chemical, and physical aspects of the adult pigment pattern. J. Morphol. 179, 229-242. doi: 10.1002/jmor.1051790303

Gelman, A., and Su, Y.-S. (2016). arm: Data Analysis Using Regression and Multilevel/Hierarchical Models. R package version 1.10-1. https:/CRAN.Rproject.org/package $=$ arm
Griffith, S. C., Parker, T. H., and Olson, V. A. (2006). Melanin- versus carotenoidbased sexual signal: is the difference really so black and red? Anim. Behav. 71, 749-763. doi: 10.1016/j.anbehav.2005.07.016

Griggio, M., Valera, F., Casas, A., and Pilastro, A. (2005). Males prefer ornamented females: a field experiment of male choice in the rock sparrow. Anim. Behav. 69, 1243-1250. doi: 10.1016/j.anbehav.2004.10.004

Günder, I. (1954). Nachweis und Lokalisation von Pterinen und Riboflavin in der Haut von Amphibien und Reptilien. Z. Vgl. Physiol. 36, 78-114. doi: 10.1007/BF00297855

Gwinner, H., and Schwabl, H. (2005). Evidence for sexy sons in European starlings (Sturnus vulgaris). Behav. Ecol. Sociobiol. 58, 375-382. doi: 10.1007/s00265-005-0948-0

Gwynne, D. T. (1991). Sexual competition among females: What causes courtship-role reversal? Trends Ecol. Evol. 6, 118-121. doi: 10.1016/0169-5347(91)90089-G

Halliday, T. R. (1977). "The Courtship of European Newts: An Evolutionary Perspective," in The Reproductive Biology of Amphibians, eds D. H. Taylor and S. I. Guttman (Boston, MA: Springer US), 185-232. doi: 10.1007/978-1-4757-6781-0_6

Halliday, T. R. (1990). "The Evolution of Courtship Behavior in Newts and Salamanders," in Advances in the Study of Behavior, eds P. J. B. Slater, J. S. Rosenblatt, and C. Beer (San Diego, CA: Academic Press), 137-169. doi: $10.1016 /$ S0065-3454(08)60202-8

Hoelzer, G. A. (1989). The good parent process of sexual selection. Anim. Behav. 38, 1067-1078. doi: 10.1016/S0003-3472(89)80146-0

Honěk, A. (1993). Intraspecific variation in body size and fecundity in insects: a general relationship. Oikos 66, 483-492. doi: 10.2307/3544943

Hõrak, P., Surai, P. F., Ots, I., and Møller, A. P. (2004). Fat soluble antioxidants in brood-rearing great tits Parus major: relations to health and appearance. J. Avian Biol. 35, 63-70. doi: 10.1111/j.0908-8857.2004.03167.x

Huber, C., Batchelor, J. R., Fuchs, D., Hausen, A., Lang, A., Niederwieser, D., et al. (1984). Immune response-associated production of neopterin. Release from macrophages primarily under control of interferon-gamma. J. Exp. Med. 160, 310-316. doi: 10.1084/jem.160.1.310

Iwasa, Y., and Pomiankowski, A. (1999). Good parent and good genes models of handicap evolution. J. Theor. Biol. 200, 97-109. doi: 10.1006/jtbi.1999.0979

Kekäläinen, J., Huuskonen, H., Tuomaala, M., and Kortet, R. (2010). Both male and female sexual ornaments reflect offspring performance in a fish. Evolution 64, 3149-3157. doi: 10.1111/j.1558-5646.2010.01084.x

Kirkpatrick, M., and Barton, N. H. (1997). The strength of indirect selection on female mating preferences. Proc. Natl. Acad. Sci. U.S.A. 94, 1282-1286. doi: 10.1073/pnas.94.4.1282

Koch, R. E., Kavazis, A. N., Hasselquist, D., Hood, W. R., Zhang, Y., Toomey, M. B., et al. (2018). No evidence that carotenoid pigments boost either immune or antioxidant defenses in a songbird. Nat. Comm. 9, 1-7. doi: 10.1038/s41467-018-02974-x

Kokko, H., Brooks, R., Jennions, M. D., and Morley, J. (2003). The evolution of mate choice and mating biases. Proc. R. Soc. B Biol. Sci. 270, 653-664. doi: $10.1098 / \mathrm{rspb} .2002 .2235$

Kokko, H., and Monaghan, P. (2001). Predicting the direction of sexual selection. Ecol. Lett. 4, 159-165. doi: 10.1046/j.1461-0248.2001.00212.x

Kopecký, O., and Šichtar, J. (2014). Sex differences in ventral side colouration of Alpine newts. Isr. J. Ecol. Evol. 60, 29-34. doi: 10.1080/15659801.2014.937078

Korner-Nievergelt, F., Roth, T., von Felten, S., Guelat, J., Almasi, B., and KornerNievergelt, P. (2015). Bayesian Data Analysis in Ecology using Linear Models with R, BUGS and Stan. London: Academic Press.

Kraaijeveld, K., Kraaijeveld-Smit, F. J. L., and Komdeur, J. (2007). The evolution of mutual ornamentation. Anim. Behav. 74, 657-677. doi: 10.1016/j.anbehav.2006.12.027

Lande, R. (1980). Sexual dimorphism, sexual selection, and adaptation in polygenic characters. Evolution 34, 292-305. doi: 10.1111/j.1558-5646.1980.tb0 4817.x

LaPlante, L. H. (2015). Female belly colour and bobbing behaviour advertise sexual receptivity in a pelagic-spawning coral reef fish. Behaviour 152, 705-725. doi: $10.1163 / 1568539 \mathrm{X}-00003250$

Lüdtke, D. U., and Foerster, K. (2018). Choosy males court both large, colourful females and less colourful but responsive females for longer. Anim. Behav. 146, 1-11. doi: 10.1016/j.anbehav.2018.09.018 
Lüdtke, D. U., and Foerster, K. (2019). Temporal patterns of mating activity in Alpine newts, Ichthyosaura alpestris. J. Herpetol. 53, 245-251. doi: 10.1670/18-129

Maag, M. (2013). Differential Male Investment: Assessing Sperm Counts in Spermatophores of the Alpine Newt (Ichthyosaura alpestris). Bachelor thesis, Eberhard-Karls Universität Tübingen.

Maia, R., Eliason, C. M., Bitton, P.-P., Doucet, S. M., and Shawkey, M. D. (2013). pavo: an R package for the analysis, visualization and organization of spectral data. Methods Ecol. Evol. 4, 609-613. doi: 10.1111/2041-210X.12069

Martin, R. A., and Pfennig, D. W. (2010). Maternal investment influences expression of resource polymorphism in amphibians: implications for the evolution of novel resource-use phenotypes. PLoS ONE 5:e9117. doi: 10.1371/journal.pone.0009117

Massironi, M., Rasotto, M. B., and Mazzoldi, C. (2005). A reliable indicator of female fecundity: the case of the yellow belly in Knipowitschia panizzae (Teleostei: Gobiidae). Mar. Biol. 147, 71-76. doi: 10.1007/s00227-004-1549-6

Matsui, K., Marunouchi, J., and Nakamura, M. (2002). An ultrastructural and carotenoid analysis of the red ventrum of the Japanese newt, Cynops pyrrhogaster. Pigment Cell Res. 15, 265-272. doi: 10.1034/j.1600-0749.2002.01085.x

McGraw, K. J. (2006). "Mechanics of uncommon colors: pterins, porphyrins, and psittacofulvins," in Bird Coloration: Volume 1 Mechanisms and Measurements, eds G. E. Hill and K. J. McGraw (Cambridge, MA: Harvard University Press), 354-398.

Miaud, C. (1994). Role of wrapping behavior on egg survival in three species of Triturus (Amphibia: Urodela). Copeia 1994, 535-537. doi: 10.2307/1447007

Miaud, C. (1995). Oviposition site selection in three species of European newts (Salamandridae) genus Triturus. Amphibia-Reptilia 16, 265-272. doi: 10.1163/156853895X00064

Miaud, C., and Merilä, J. (2001). Local adaptation or environmental induction? Causes of population differentiation in alpine amphibians. Biota 2, 31-50.

Nordeide, J. T. (2002). Do male sticklebacks prefer females with red ornamentation? Can. J. Zool. 80, 1344-1349. doi: 10.1139/z02-116

Obika, M. (1963). Association of pteridines with amphibian larval pigmentation and their biosynthesis in developing chromatophores. Dev. Biol. 6, 99-112. doi: 10.1016/0012-1606(63)90007-1

Oettl, K., and Reibnegger, G. (2002). Pteridine derivatives as modulators of oxidative stress. Curr. Drug Metab. 3, 203-209. doi: 10.2174/1389200024605127

Olson, V. A., and Owens, I. P. F. (1998). Costly sexual signals: are carotenoids rare, risky or required? Trends Ecol. Evol. 13, 510-514. doi: 10.1016/S0169-5347(98)01484-0

Parker, T. H. (2003). Genetic benefits of mate choice separated from differential maternal investment in red junglefowl (Gallus gallus). Evolution 57, 2157-2165. doi: 10.1111/j.0014-3820.2003.tb00393.x

Pérez-Rodríguez, L. (2009). Carotenoids in evolutionary ecology: re-evaluating the antioxidant role. BioEssays 31, 1116-1126. doi: 10.1002/bies.200900070

Pilastro, A., Griggio, M., and Matessi, G. (2003). Male rock sparrows adjust their breeding strategy according to female ornamentation: parental or mating investment? Anim. Behav. 66, 265-271. doi: 10.1006/anbe.2003.2203

Pitcher, T. E., and Evans, J. P. (2001). Male phenotype and sperm number in the guppy (Poecilia reticulata). Can. J. Zool. 79, 1891-1896. doi: 10.1139/z01-142

Price, T., Schluter, D., and Heckman, N. E. (1993). Sexual selection when the female directly benefits. Biol. J. Linn. Soc. 48, 187-211. doi: 10.1111/j.1095-8312.1993.tb00887.x,

R Core Team (2018). R: A Language and Environment for Statistical Computing. Available online at: https://www.r-project.org/.

Ressel, S., and Schall, J. J. (1989). Parasites and showy males: malarial infection and color variation in fence lizards. Oecologia 78, 158-164. doi: 10.1007/BF00377151
Rosenqvist, G., and Berglund, A. (2011). Sexual signals and mating patterns in Syngnathidae. J. Fish Biol. 78, 1647-1661. doi: $10.1111 / \mathrm{j} .1095-8649.2011 .02972 . \mathrm{x}$

Rosenthal, G. G. (2017). Mate Choice: The Evolution of Sexual Decision Making from Microbes to Humans. Princeton, NJ: Princeton University Press.

Servedio, M. R., and Lande, R. (2006). Population genetic models of male and mutual mate choice. Evolution 60, 674-685. doi: 10.1111/j.0014-3820.2006.tb01147.x

Steinicke, H. (1976). Beiträge zum Problem unvollständiger Auspigmentierung bei der Aufzucht der Chinesischen Rotbauchunke (Bombina orientalis). Salamandra 12, 23-26.

Svensson, P. A. (2006). Female Coloration, Egg Carotenoids and Reproductive Success: Gobies as a Model System. PhD, Norwegian University of Science and Technology.

Taylor, D. H., and Guttman, S. I. (1977). The Reproductive Biology of Amphibians. Boston, MA: Springer US.

Thiesmeier, B., and Schulte, U. (2010). Der Bergmolch: im Flachland wie im Hochgebirge zu Hause. Bielefeld: Laurenti.

Thomas, M., Rottscheidt, R., Weddeling, K., and Tarkhnishvili, D. (2002). Methodenvergleich zur Ermittlung der Fekundität von Berg- (Triturus alpestris) und Teichmolch (T. vulgaris). Zeitschrift für Feldherpetologie 9, 17-23.

Torres, R., and Velando, A. (2005). Male preference for female foot colour in the socially monogamous blue-footed booby, Sula nebouxii. Anim. Behav. 69, 59-65. doi: 10.1016/j.anbehav.2004.03.008

Verrell, P. A. (1986). Limited male mating capacity in the smooth newt, Triturus vulgaris vulgaris (Amphibia). J. Comp. Psychol. 100, 291-295. doi: 10.1037/0735-7036.100.3.291

Verrell, P. A., Halliday, T. R., and Griffiths, M. L. (1986). The annual reproductive cycle of the Smooth newt (Triturus vulgaris) in England. J. Zool. 210, 101-119. doi: 10.1111/j.1469-7998.1986.tb03623.x

von Lindeiner, A. (1992). Untersuchungen zur Populationsökologie von Berg-, Faden- und Teichmolch (Triturus alpestris L., T. helveticus Razoumowski, T. vulgaris L.) an ausgewählten Gewässern im Naturpark Schönbuch (Tübingen). Verlag für Ökologie und Faunistik.

Weiss, S. L., Foerster, K., and Hudon, J. (2012). Pteridine, not carotenoid, pigments underlie the female-specific orange ornament of striped plateau lizards (Sceloporus virgatus). Comp. Biochem. Physiol. Part Biochem. Mol. Biol. 161, 117-123. doi: 10.1016/j.cbpb.2011.10.004

Weiss, S. L., Kennedy, E. A., Safran, R. J., and McGraw, K. J. (2011). Pterinbased ornamental coloration predicts yolk antioxidant levels in female striped plateau lizards (Sceloporus virgatus). J. Anim. Ecol. 80, 519-527. doi: 10.1111/j.1365-2656.2010.01801.x

Wong, B. B. M., and Svensson, P. A. (2009). Strategic male signalling effort in a desert-dwelling fish. Behav. Ecol. Sociobiol. 63, 543-549. doi: 10.1007/s00265-008-0689-y

Ziegler-Günder, I. (1956). Pterine: pigmente und Wirkstoffe im Tierreich. Biol. Rev. 31, 313-345. doi: 10.1111/j.1469-185X.1956.tb0 1593.x

Conflict of Interest: The authors declare that the research was conducted in the absence of any commercial or financial relationships that could be construed as a potential conflict of interest.

Copyright (c) 2019 Lüdtke and Foerster. This is an open-access article distributed under the terms of the Creative Commons Attribution License (CC BY). The use, distribution or reproduction in other forums is permitted, provided the original author(s) and the copyright owner(s) are credited and that the original publication in this journal is cited, in accordance with accepted academic practice. No use, distribution or reproduction is permitted which does not comply with these terms. 